\title{
La eficacia de la comunicación de las organizaciones del Tercer Sector en los vídeos emitidos a través de YouTube.
}

\author{
Isidoro Arroyo Almaraz \\ Universidad Rey Juan Carlos. Madrid \\ isidoro.arroyo@urjc.es \\ Miguel Baños GonzÁLEZ \\ Universidad Rey Juan Carlos. Madrid \\ miguel.banos@urjc.es
}

\begin{abstract}
Resumen
Las redes sociales se utilizan para comunicar objetivos del cambio social. Nuestra finalidad es reflexionar sobre qué valor aportan los vídeos emitidos a través de YouTube por organizaciones del Tercer Sector para predecir su eficacia por su potencial capacidad viral. Recurriendo al modelo de análisis de contenido predictivo definimos los perfiles característicos de los mensajes emitidos y medimos la eficacia potencial de cada perfil analizando la recepción. Fusionando datos obtenidos de ambos análisis definimos qué factores del mensaje pueden ser indicadores predictivos de viralidad.
\end{abstract}

Palabras clave: Tercer Sector; análisis predictivo; publicidad social; eficacia publicitaria; redes sociales.

\section{Non profit communication effectiveness in the YouTube videos}

\begin{abstract}
The social networks are used to communicate social change goals. Our aim is to reflect on the value provided by the video contents shared in YouTube by non-profit sector organizations to predict their viral effectiveness. Based on the predictive content analysis model a profiled sample of the most representative messages shared has been defined to measure the potential effectiveness of each of them according to the results of analyzing the reception. The combination of the results of both analyses allows identifying some factors that shall be considered indicators of the virality effectiveness.
\end{abstract}

Key words: Third sector; predictive content analysis; social advertising; advertising effectiveness; social Networks.

\section{Referencia normalizada:}

Arroyo Almaraz, I.; Baños González, M. (2013) La eficacia de la comunicación de las organizaciones del Tercer Sector en los vídeos emitidos a través de Youtube. Historia y Comunicación Social. Vol. 18 No Especial Octubre. Págs. 615-626.

Sumario: 1. Introducción. 2. Objetivos y metodología. 3. Resultados. 3.1. Resultados del análisis de los mensajes audiovisuales. 3.2. Resultados del análisis de la recepción. 4. Conclusiones. 4.1. Conclusiones particulares del análisis de los mensajes audiovisuales. 4.2. Conclusiones particulares del análisis de la recepción. 4.3. Conclusiones generales. 5. Referencias bibliográficas. 


\section{Introducción}

Las organizaciones del Tercer Sector están utilizando las redes sociales por su gran capacidad para comunicar los objetivos del cambio social y potenciar la inclusión de todos los agentes transformadores implicados: voluntarios, colaboradores, beneficiarios, etc. Para lograrlo se crean comunidades virtuales donde todos pueden interactuar teniendo como objetivo la inclusión y la transformación social bajo el paradigma de que los beneficios del estado de bienestar son necesarios $\mathrm{y}$, por tanto, deben ser posibles y esto tiene que hacerse real.

Los medios sociales: redes sociales, blogs, wikis, etc. se están mostrando de forma particular y en la interacción de unos con otros como los más idóneos para la consecución de los objetivos de esta comunicación social del Tercer Sector; se pasa de la comunicación en las redes sociales a la movilización en la calle con la ocupación del espacio público y, a desde ahí, se salta a los medios tradicionales de comunicación de masas (publicity), como sucedió en Madrid con el movimiento 15-M o en Nueva York con el movimiento Occupy Wall Street. Desde hace ya algún tiempo la sociedad civil viene movilizándose a través de las redes sociales para proponer nuevos diálogos a las instituciones con propuestas que convierten en real lo que es necesario, así también lo afirma Cortina cuando dice que: "La sociedad civil viene movilizándose desde hace tiempo en los medios de comunicación, en intervenciones públicas, en las redes, en las calles, poniendo sobre el tapete a la vez críticas y propuestas realizables" (2013: 37)

Los medios sociales, cada vez más, se apoyan en la presencia del vídeo viral para ser compartido y comentado en las redes sociales y, en este sentido, YouTube cumple una labor fundamental como distribuidor de esos vídeos, desde donde serán dados a conocer a través de las redes sociales: Facebook, Twitter, Tuenti, etc.

El objeto de estudio de esta investigación, que forma parte del proyecto de investigación CSO2009-11203 financiado por el Ministerio de Ciencia e Innovación (Programa Nacional de Proyectos de Investigación Fundamental, VI Plan Nacional de Investigación Científica, Desarrollo e Innovación Tecnológica 2010-2013), es reflexionar sobre qué valor aportan los vídeos emitidos a través de YouTube por organizaciones del Tercer Sector para predecir su eficacia por su potencial capacidad viral.

Se parte de la hipótesis de que las organizaciones del Tercer Sector están obligadas a acercarse más a los ciudadanos y actuar como ONG 2.0, comunicando mejor las tareas que llevan a cabo y se tienen que valer, cada vez más, del uso de vídeos en Internet, ya que el efecto viral que se consigue con ellos, en muchas ocasiones, hace que todas las organizaciones y particularmente aquellas que no tienen muchos recursos y tienen estructuras reducidas, puedan multiplicar la eficacia de sus mensajes.

Para que el efecto viral de los vídeos de YouTube se produzca, se necesita un vídeo capaz de captar la atención del internauta y provocar su deseo de compartirlo con otras personas con las que está conectado a través de las diferentes redes sociales. 
Una vez creado el vídeo viral, es necesario seleccionar la red social más adecuada para difundirlo; a pesar de que es muy sencillo incluir vídeos en blogs, Twitter, Facebook, o compartir vídeos a través de YouTube, no es tan fácil conseguir el deseado efecto viral.

Estos efectos de los vídeos nos acercan a la cultura que el sociólogo Zygmunt Bauman (2010) bautizó como "modernidad líquida". Un nuevo patrón cultural de sociedad en constante cambio y que adopta formas cambiantes (líquidas), contrapuesto al modelo de solidez de los medios de comunicación tradicionales caracterizados por la estabilidad. Por tanto, de una parte la crisis económica, de otra parte, los avances tecnológicos en la comunicación y especialmente la explosión de las redes sociales, están favoreciendo este cambio de cultura desde lo sólido a lo líquido.

Ya sólo se habla de comunicación dialógica y horizontal para construir la inteligencia colectiva, la que se realiza con el trabajo de todos los agentes solidarios, es el trabajo de todos y la pluralidad de ideas la que garantiza esa inteligencia ampliada porque, como señala Cortina: "Son los diálogos los que permiten ir incorporando en las instituciones las propuestas más lúcidas y fundamentadas, las que pueden (...) crear una sociedad más justa" (2013: 37).

Hemos observado en nuestras investigaciones precedentes que cada vez son más las organizaciones que utilizan las redes sociales en su estrategia de comunicación en la web 2.0.

Cuadro 1. Informes de utilización de redes sociales por el Tercer Sector

\begin{tabular}{|c|c|c|c|c|c|}
\hline \multirow{4}{*}{ Medios Sociales } & \multicolumn{5}{|c|}{ Estudios } \\
\hline & \multicolumn{3}{|c|}{ Norteamericanos } & \multicolumn{2}{|r|}{ Españoles } \\
\hline & \multirow{2}{*}{$\begin{array}{c}\text { Idealware } \\
2010\end{array}$} & \multicolumn{2}{|c|}{ BechmarkReport } & \multirow{2}{*}{$\begin{array}{c}\text { AIMC } \\
2011\end{array}$} & \multirow{2}{*}{$\begin{array}{c}\text { ONGD (AECID ) } \\
2011\end{array}$} \\
\hline & & 2011 & 2012 & & \\
\hline Facebook & $73 \%$ & $89 \%$, & $93 \%$ & $90 \%$ & $81 \%$ \\
\hline Twitter & $56 \%$ & $57 \%$ & $74 \%$ & $36,9 \%$ & $58 \%$ \\
\hline Blogs: propio, Blogger o Wordpress & $45 \%$ & $45 \%$ & & & $51 \%$ \\
\hline Youtube & $49 \%$ & $49 \%$ & $66 \%$ & & $53 \%$ \\
\hline Plataformas para compartir fotos: Flickr, etc. & $36 \%$ & $36 \%$ & $32 \%$ & & $46 \%$ \\
\hline LinkedIn & $25 \%$ & $25 \%$ & & $16,9 \%$ & $41 \%$ \\
\hline Otras redes Myspace (USA),Tuenti (España) & $17 \%$ & $17 \%$ & & $16,9 \%$ & $25 \%$ \\
\hline
\end{tabular}

Fuente: Elaboración propia

Se observa en el cuadro 1 una tendencia general de aumento de la utilización de las redes sociales y las plataformas de distribución de vídeos en las comunicaciones de las organizaciones del Tercer Sector. Esto es así, porque en todos estos formatos y/o canales es esencial la presencia del vídeo viral para ser compartido y comentado en las diferentes redes sociales.

Los vídeos consumidos desde España en YouTube están más relacionados con temas locales que globales. De esta forma, las cuestiones locales trascienden pudiendo llegar a convertirse en motivos de atención global. 
Los vídeos on-line funcionan actualmente como motores del sector publicitario por su gran capacidad para la segmentación de audiencias y su facilidad para evaluar el engagement con sus públicos, lo que resulta especialmente útil para las organizaciones del Tercer Sector.

YouTube es la segunda web con mayor tráfico de visitas en España, según el IV Estudio Anual de Redes Sociales de Interactive Advertising Bureau (IAB Spain, 2013) donde tenemos que el $64 \%$ de los internautas españoles encuestados visita con regularidad YouTube. YouTube solo es superada por Facebook (el 96\% la visita con regularidad), pero está por delante de Tuenti (35\%), de Twitter con un 46\%), Google $+(29 \%)$ y el resto ya muy alejadas de estas cifras.

La sociedad civil, como señala Cortina (2013), está asumiendo la responsabilidad, cada vez más, de proponer otro mundo posible. Y las organizaciones del Tercer Sector, que forman parte de esa sociedad civil, siguen esta tendencia y utilizan, entre otros medios sociales, YouTube para promocionar sus mensajes a través de vídeos debido al bajo coste con el que pueden difundir sus objetivos, siempre buscando un efecto de viralidad a través de las llamadas técnicas de marketing WOM digital o "buzz marketing".

La comunicación en redes sociales, que contribuye al triunfo de la opinión veloz y con ello nos convierte a todos en especialistas potenciales con información on line a golpe de ratón, construye un nuevo sistema de valores democráticos, pero que atribuye a lo más visto el poder de la verdad. El poder de lo visible y lo audible, que realza lo emocional, se entrona frente al poder de los mensajes que realzan lo racional.

La nueva inteligencia colectiva tan positiva en pluralidad y presencia de la sociedad civil en espacios compartidos, también presenta algunos riesgos; muchas de las filias que se generan a través de las redes sociales se sustentan en vínculos de afición, amistad, edad, proyectos temporales, etc.

Hablamos, por tanto, de vínculos débiles que forman colectividades efímeras basadas en la comparecencia en espacios públicos a través de flashmob o virtuales a través de vínculos como I like de Facebook o los Retweet de Twitter que funcionan bien para acciones inmediatas pero que no van más allá de agrupamientos puntuales. Son relaciones sin los viejos compromisos que apoyaban la solidaridad en las creencias derivadas de las ideologías, de los vínculos políticos y las convicciones morales, y que configuraban una sociedad política que se ocupaba de los intereses universales, en una época en la que se consideraba que la sociedad civil era solo aquella que se preocupaba por sus intereses particulares.

Esta nueva comunicación basada en la afinidad de intereses, genera una nueva creatividad que busca enganchar y seducir a los sujetos, haciéndoles partícipes de los espacios que generan con su propia experiencia vital. Son nuevos espacios donde los individuos se comprometen e identifican simbólicamente a través de vínculos pasajeros. Como señala Zafra (2010), el beneficio de estos vínculos es que reduce, gracias a lo efímero, los fanatismos al no estar cohesionadas las comunidades por 
vínculos fuertes. Y que estas nuevas comunidades funcionan más por afinidad que por identidad.

Las organizaciones de Tercer Sector comunican a través de las redes sociales recurriendo a este modelo participativo y directo, donde consiguen multiplicar el efecto de sus mensajes para llegar a un mayor compromiso posterior mediante donaciones, voluntariado, etc. Sin embargo, a pesar de la relevancia que han adquirido las redes, creemos que aún no se aprovechan las verdaderas posibilidades que ofrecen.

Entendemos que existen dos tipos de frenos: internos y externos, ambos obstaculizan un uso más eficaz de las redes sociales. Entre los frenos internos tenemos la falta de apoyo de los estamentos directivos que las consideran con menos visibilidad e impacto que los medios convencionales; además, está la escasez recursos con los que suelen contar estas organizaciones para la gestión de su comunicación. Entre los frenos externos está la pérdida de control de los procesos de comunicación en las redes; otro problema es la multiplicidad de perfiles de una organización en la misma red o en diferentes redes derivado de la existencia de múltiples organizaciones locales o internacionales lo que genera confusión sobre el origen y la autoría de los mensajes.

Asimismo, la medición de la eficacia de los mensajes en redes sociales no es una actividad prioritaria de las organizaciones del Tercer Sector; prueba de ello son las pocas organizaciones que lo hacen y la escasez de sus observaciones, que apenas pasan de medir el número de fans o visitas que reciben en el perfil (Arroyo, Baladrón, Martín, 2013).

También se ha observado la necesidad de mejorar la adaptación de los mensajes al estilo característico de las redes sociales, así como valorar más la creatividad en los contenidos y la innovación en los formatos con el objetivo de llegar más eficazmente a los públicos (Arroyo, Baños

y Van Wyk, 2013). Diseños llamativos, cercanos y personalizados; formatos más concisos y visuales; contactos más personales con públicos mejor segmentados. Está conclusión está corroborada por otros estudios, de ahí que en ocasiones se hable de una «comunicación previsible donde las ONG cuentan lo que hacen, lo que hace falta hacer, pero no construyen mensajes que capten la atención y circulen por la red» (Arroyo, Baños y Rodríguez, 2012: 15).

\section{Objetivos y metodología}

\subsection{Objetivos de la investigación}

El éxito alcanzado por algunas campañas en las redes sociales, que han llegado a millones de individuos, ha animado a todo tipo de organizaciones a recurrir a estas técnicas de comunicación; sin embargo, la realidad demuestra que en muy pocas ocasiones se logra la notoriedad y la eficacia esperada. 
Por eso, en esta investigación tenemos dos grandes objetivos que se corresponden con las dos fases en las que se divide el estudio.

Nuestro primer objetivo es llegar a definir cuáles son los perfiles característicos de los elementos de la construcción de los mensajes que las organizaciones del Tercer Sector, de acuerdo con una serie de variables formales, de contenido y de significación, emiten a través de las redes sociales.

Para la segunda fase, el objetivo es medir la eficacia analizando la recepción de los mensajes para, por último, predecir su potencial para llegar a los públicos a través de las redes sociales.

\subsection{Diseño metodológico y procedimientos}

La metodología de esta investigación descansa en un modelo de análisis de contenido predictivo (Neuendorf, 2002), que integra, por un lado, el análisis de contenido tradicional y, por otro, el análisis de recepción. Los resultados obtenidos de la aplicación de estas técnicas, y aplicados estadísticos inferenciales y explicativos, nos permitirán llegar a conclusiones en relación con el comportamiento de los mensajes e identificar aquellos factores del mensaje que se convierten en indicadores para predecir determinados efectos en los públicos; en otras palabras, nos permite predecir el resultado de un mensaje tipo en una audiencia concreta (Baños González y Rodríguez García, 2009).

Esta metodológica se desarrolla a través de diferentes etapas de investigación:

1. Diseño de una muestra representativa de todo tipo de mensajes que sirvan a causas de interés social, creados o producidos en nuestro país, y emitidos por el Tercer Sector en redes sociales; finalmente seleccionamos 370 mensajes de aquellas organizaciones que tienen canal propio en YouTube. En esta etapa también se definen las variables formales, de contenido y de significación a analizar.

2. Análisis de los mensajes audiovisuales que forman parte de la muestra para establecer cuáles son los perfiles o modelos característicos de estos mensajes observando y midiendo la presencia y el comportamiento de las variables: en primer lugar, estudio descriptivo para analizar las características de los mensajes en el que se observan las medidas y la distribución de frecuencias y se establecen las tendencias en la construcción de los mensaje que se pueden considerar dominantes; en segundo lugar, a través del análisis de correlación bi-variada se conoce el grado de fuerza de la relación entre las variables. Con los resultados obtenidos se dispone de la información necesaria para construir los mensajes prototipo que utilizaremos en la fase experimental y que nos permitirán medir los efectos y la eficacia de los mensajes.

Para evaluar las variables utilizamos un grupo de veinte jueces, previamente formados para realizar la tarea; con los jueces se evita la subjetividad que supone la valoración de un sólo evaluador y, al formar un grupo con un número suficiente de evaluadores se evitan coincidencias producto del azar. 
3. Etapa de carácter experimental donde se crean y producen prototipos característicos de mensaje audiovisual teniendo en cuenta los resultados obtenidos en la etapa anterior. Se elaboran mensajes con unos perfiles creativos muy diferenciados, pero con el mismo contenido ya que todos ellos se generan partiendo del briefing de la ONG Movimiento por la Paz, que participa en la investigación. Para el experimento, la ONG creó una página de Facebook (optamos por esta red social a partir de los resultado obtenidos de un grupo de discusión que puso de relieve las características de las principales redes sociales) que pretende ser su página de fans, con el logo, los símbolos y los detalles principales de la organización para crear esta impresión. Y a este espacio se suben los anuncios que se deben analizar y se invita a un grupo de 64 estudiantes de la universidad de Málaga a visitar la página durante un mes para poder medir y evaluar las acciones.

4. Se analiza la recepción y los efectos de estos mensajes en los receptores. Estudiamos el modo en el que las variables analizadas en los mensajes audiovisuales se pueden asociar con su eficacia, estableciendo diferentes grados o niveles de influencia. En esta situación real comprobaremos la influencia de cada variable independiente en la audiencia mediante un análisis cuantitativo y cualitativo tanto de la interacción que se realiza con los mensajes como de las opiniones derivadas de los diferentes mensajes.

5. Análisis estadístico inferencial y predictivo de los datos obtenidos.

\section{Resultados}

\subsection{Resultados del análisis de los mensajes audiovisuales}

A través de este análisis observamos que en los mensajes emitidos por las ONG a través de las redes sociales, se presta más atención a los contenidos que a la forma que adoptan esos contenidos; $\mathrm{y}$, también, se tiende a incluir abundante información que se muestra de una forma muy visible y clara. Además, se observa una tendencia a recurrir a formas narrativas básicas y presentan características habituales de un spot creado y producido para el medio televisivo; los niveles de creatividad suelen ser bajos y, cuando destacan por ella, se recurre, fundamentalmente, a géneros como el humor, la comparación o el problema-solución.

También hemos observado que, a pesar de las tendencias generales descritas en el párrafo anterior, se identifican unas estructuras básicas que subyacen en este tipo de mensajes, que podemos agrupar en torno a dos perfiles dominantes:

Un perfil o modelo eminentemente informativo que destaca por incorporar unos contenidos muy concretos, sencillos y denotativos; en el que una persona, en el papel de presentador, suele hablar, en tercera persona, de la organización que firma el mensaje; recurren a espacios fácilmente identificables; suelen tener textos con mucha 
información y la identidad visual corporativa suele aparecer en una posición destacada en primer término; nos encontramos con unos niveles retóricos mínimos; etc.

El segundo perfil dominante muestra un carácter más creativo y persuasivo. Su duración es más próxima a la de un spot convencional (en torno a 30 segundos) donde alguien transmite su testimonio en primera persona sobre las experiencias que ha tenido con la organización; al contrario de lo que sucedía en el perfil anterior, hay ideas implícitas, contenidos poco concretos, complejos y con tendencia a la polisemia; no suelen incluir textos; nos encontramos con unos niveles retóricos altos; etc.

\subsection{Resultados del análisis de la recepción}

El 87,5\% de los participantes en el estudio se convirtieron en fans de la página creada para esta fase de la investigación al elegir la opción "Me gusta".

En cuanto a su interacción con la página, se obtuvieron 1.859 visionados a lo largo del mes que duró el estudio, dejaron 155 comentarios y 203 visitas al "muro" que es la parte principal de la página. Se observa un incremento progresivo de la participación de los sujetos en la actividad a lo largo de todo el mes.

En relación con los usuarios que se hicieron fans de la página, la proporción de hombres y mujeres es similar a la de la muestra por lo que no podemos considerar que la variable sexo sirva para establecer diferencias en el interés por la publicidad social.

Si resulta interesante que el número de fans es muy superior al de sujetos participantes lo que pone de relieve la capacidad de propagación de la página a pesar de no realizar ningún tipo de comunicación sobre ella.

El número de impresiones o veces que un contenido asociado a la página es visitado, tuvo un incremento positivo cada día del experimento con picos de hasta el $70 \%$.

También se incrementó la audiencia potencial de la página medida por el número de contactos de nuestros fans que pudieron verla, superando los 13.000 el último día del experimento.

En cuanto a la expansión y a la viralidad de los mensajes investigados en esta fase, a partir de los sujetos seleccionados, vemos como los contenidos de la página diseñada para el experimento se extienden por la red llegando a un número de usuarios que multiplicar por 10 el sujetos que formaban parte de la muestra y con unas características sociodemográficas mucho más amplias.

Por último, los mensajes que hemos calificado como más creativos, han recibido un número de comentarios positivos muy superior al que han recibido los mensajes con un carácter más informativo: y los primeros también han conseguido un número mucho mayor de "Me gusta" que los segundos mensajes. 


\section{Conclusiones}

\subsection{Conclusiones particulares del análisis de los mensajes}

En primer lugar, podemos concluir que los mensajes emitidos por las organizaciones que se integran dentro del Tercer Sector muestran unas características muy similares, son comunicaciones muy previsibles y, en general, con unos niveles de creatividad bajos. Suelen ser mensajes que se limitan a incluir información de alguna cuestión relacionada con la organización de una forma clara y simple. En conjunto, observamos dos modelos o perfiles en los que se pueden encuadrar la mayoría de los mensajes analizados: uno de carácter básicamente informativo, y otro con un carácter más creativo y persuasivo.

De acuerdo con los resultados se observa que el foco de interés se centra en los contenidos que se desean transmitir, dejando en un segundo plano la forma que adoptan los mensajes para transmitir esos contenidos.

Esto nos lleva a pensar que el problema puede deberse a las decisiones estratégicas poco acertadas que se toman o a la escasez de recursos que caracterizan a los departamentos de comunicación de este tipo de organizaciones. Pensamos que, en la mayoría de los casos, el motivo real tiene que ver más con los recursos ya que se observa una tendencia a reutilizar mensajes de todo tipo (spots, entrevistas, noticias...) ya emitidos por otros medios.

El resultado de todo esto es la utilización de mensajes que no aprovechan el verdadero potencial de las redes sociales como herramientas de comunicación al servicio de las organizaciones como puede ser el ciberactivismo, la capacidad para dialogar con los públicos, la viralidad...

\subsection{Conclusiones particulares del análisis de la recepción}

La primera gran conclusión es que los internautas muestran su preferencia por los mensajes con un perfil más creativo y connotativo frente a los que muestran un perfil marcadamente informativo y denotativo.

Por otra parte, se advierte que este tipo de mensajes obtienen una amplia difusión incrementándose el número de usuarios potenciales con cada nuevo contacto que entra en la perfil creado en la red social.

También se observa cómo los comentarios y la participación de los usuarios tiene un gran potencial para mejorar la viralidad del mensaje e incrementar el número de visionados.

Por último, se observa una tendencia por parte de los usuarios no solamente a ver los contenidos del perfil sino también a interactuar con ellos; una tendencia que se incrementó con el paso de los días, de tal forma que, además del potencial que muestran las redes sociales para la conectividad, también ofrece la posibilidad de 
crear un mensaje colectivo que parte del mensaje inicial y se completa con todos los comentarios realizados por los usuarios.

\subsection{Conclusiones generales}

Se comprueba un escaso aprovechamiento que las organizaciones del Tercer Sector hacen de las redes sociales y de su viralidad; se hace necesario revisar los papeles que se dan en la interacción social teniendo en cuenta las demandas actuales del contexto en el que se mueven, tal y como señalan Durán y Fernández (2010).

Se hace imprescindible la innovación en casi todos los ámbitos y, especialmente, en las comunicaciones que estas organizaciones llevan a cabo, sobre todo si quieren sobrevivir en un contexto de crisis como el que estamos viviendo en el que se hace más necesaria que nunca la financiación privada, y, como señala Moreno (2008), la creatividad puede ser la mejor ayuda a para abrir nuevos caminos. En el terreno de la innovación en comunicaciones las redes sociales son una clara alternativa a los medios convencionales con una gran variedad de herramientas de comunicación que demandan más que recursos económicos, pensamiento estratégico y creatividad. Y la necesaria adaptación a las nuevas herramientas afecta por igual a todas las organizaciones del Tercer Sector porque para mejorar su imagen entre el público tienen que diseñar estrategias de comunicación adecuadas a los objetivos que se han marcado (Arroyo, Martín y Farfán, 2013).

La viralidad y las noticias sobre vídeos con millones de visitas están haciendo que muchas organizaciones sin grandes recursos recurran a estas fórmulas pero como ya se ha demostrado (Arroyo, Baños y Rodríguez, 2012) para conseguir la viralidad, es imprescindible contar con un mensajes que capte la atención y despierte el deseo en los sujetos de compartirlo a través de las redes sociales; sin él no se conseguirá la viralidad perseguida.

La participación activa de los usuarios que crean el mensaje colectivo facilita el recuerdo e incrementa el grado de compromiso que tienen con la organización que pone en marcha la acción lo que se muestra como un factor decisivo para la publicidad social, tal y como ponen de relieve Méndiz, Victoria y Arroyo (2013).

Para finalizar, también se percibe que los jóvenes, que son quienes más consumen este tipo de mensajes y herramientas, perciben los mensajes denotativos como anuncios creados para otros medios que son transferido directamente al mundo on line. Sin embargo, como señalan Méndiz, Victoria y Arroyo (2013), lo que más valoran los internautas de las comunicaciones que se realizan a través de las redes sociales, es la sencillez, la retórica, la interactividad y la participación emocional, mensajes que facilitan la viralidad en entornos de colaboración como es el de las redes sociales. 


\section{Referencias bibliográficas}

ARROYO, I., BALADRÓN, A. J., MARTÍN, R. (2013). "La comunicación en redes sociales: percepciones y usos de las Ong españolas". En Cuadernos de Información, vol. 32. Santiago de Chile: Pontificia Universidad Católica de Chile. p.7788. http://cuadernos.uc.cl/uc/index.php/CDI/article/view/497 [10-09-2013].

ARROYO, I. y BAÑOS, M. (2013). "Tendencias de la comunicación del Tercer Sector en la web 2.0. Análisis retórico de los tropos". En: Icono 14, volumen 11 (2), Madrid: Icono 14, Madrid: Icono 14. p. 331-356: http://www.icono14.net/ojs/ index.php/icono14/article/view/556/429 doi: 10.7195/ ri14.v11i2.556 [20-092013].

ARROYO I. y BAÑOS, M. y VAN WYCK, C. (2013). "Análisis de los mensajes audiovisuales del Tercer Sector en YouTube". En Revista Latina de Comunicación Social, $\mathrm{n}^{\circ}$ 68, La Laguna (Tenerife): Universidad de La Laguna. p.328-354 http:// www.revistalatinacs.org/068/paper/980_Madrid/14_Arroyo.html DOI: 10.4185/ RLCS-2013-980/CrossRef link [27-08-2013]

ARROYO, I., MARTÍN NIETO, R., FARFÁN, J. (2013). “Usos, percepciones y potencialidades de las redes sociales en la construcción de las marcas". En: Doxa Comunicación, $\mathrm{n}^{\circ}$ XVI, Madrid: CEU san Pablo. p. 129-149.

ARROYO, I., BAÑOS, M. y RODRÍGUEZ, T. (2012). "Modelo de investigación de las piezas audiovisuales de las organizaciones del tercer sector en redes sociales". En MORAGAS, M. LÓPEZ, B. y GARCÍA, R. (2012). Comunicación y Riesgo. Tarragona: Actas del Congreso AE-IC 2012. p. 1-18.

BAÑOS, M. y RODRÍGUEZ, T. C. (2009). "Desarrollo de un modelo de predicción de la eficacia para la publicidad social". En: Icono 14, $\mathrm{n}^{\circ} 13$, Madrid: Icono 14. p. 214-238: http://www.icono14.net/ojs/index.php/icono14/article/view/324 [20-102012].

BAUMAN, Z. (2010) Vida líquida. Barcelona: Ediciones Paidós Ibérica, S.A.

CORTINA, A. (2013) Una sociedad civil en ebullición. El Pais, 6/10/2013 p. 37.

DURÁN, P. y FERNÁNDEZ, M. B. (2010): "La comunicación en las organizaciones del tercer sector". En: Revista Latina de Comunicación Social, $\mathrm{n}^{\mathrm{o}}$ 65. La Laguna (Tenerife). p. 595-603: http://www.revistalatinacs.org/10/art3/921_Puebla/42_Duran.html DOI: 10.4185/RLCS-65-2010-921-595-603 [17-04-2012].

IAB Spain (2013). IV Estudio Anual de Redes Sociales. En http://www.iabspain.net/ redes-sociales/ [07-09-2013].

MÉNDIZ, A., VICTORIA, J. S. y ARROYO, I. (2013). "La eficacia de la publicidad social en las redes sociales. Un experimento online con usuarios jóvenes". En: Razón y palabra, $\mathrm{n}^{\mathrm{o}}$ 82. p.1-19. http://www.razonypalabra.org.mx/N/N82/ V82/25 MendizVictoriaArroyo V82.pdf [20-06-2013].

MORENO, J. (2008) "La creatividad puede ayudar a las ONG a abrir caminos hasta el momento impensables". En: Canalsolidario.org. http://www.canalsolidario. org/noticia/la-creatividad-puede-ayudar-a-la [24-04-2012].

NEUENDORF, K.A. (2002). The Content Analysis Guidebook. Thousand Oaks, CA: Sage. 
ZAFRA, R. (2010). Un cuarto propio conectado. (Ciber)espacio y (auto)gestión del yo. Madrid: Fórcola.

\section{Los autores}

Isidoro Arroyo Almaraz es doctor en Ciencias de la Información por la U.C.M. y Master en Técnicas de Comunicación en Servicios Sociales UCM-IMSERSO. Profesor Titular de Universidad. Profesor Visitante en diferentes universidades europeas e iberoamericanas. Autor de múltiples libros, el último: "Tendencias y Eficacia de la Comunicación Audiovisual de las Organizaciones sin Ánimo de Lucro en Redes Sociales" (Dykinson, 2012). Director del Festival y Jornadas Internacionales Solidar\&dar y miembro del Jurado: Publifestival Social (Málaga), Smile Festival (Madrid), Equidar y Rally Creativo (Argentina). IP "Desarrollo de un modelo de eficacia de la comunicación persuasiva del tercer sector en redes sociales" (CS0200911203).

Miguel Baños González es doctor en Ciencias de la Información por la UCM. Profesor Titular de Universidad. Profesor Invitado en la Universidad Empresarial Siglo 21 y en la Universidad Nacional de Córdoba (Argentina). Autor de Imagen de marca y product placement (ESIC, 2012), Las palabras en la publicidad (Laberinto, 2009), Al filo de la verdad. Historias de la publicidad en el cine (CIE Dossat, 2005). Líneas de investigación: La publicidad social en las redes sociales. Influencia de los métodos de incentivación de la creatividad en la Creatividad Publicitaria. Medida de la eficacia del product placement. Creativo y director creativo en diferentes agencias nacionales e internacionales entre 1986 y 2004. 